\title{
Administración local y sistema administrativo. La interrelación procedimental y telemática de registro, archivo y secretaría
}

\author{
Ángel Sánchez Blanco \\ Catedrático de Derecho Administrativo \\ Universidad de Málaga
}

\begin{abstract}
Sumario: I. INTRODUCCIÓN. II. LAS APORTACIONES SISTÉMICAS DE LOS ARTÍCULOS 37, 38 y 45 DE LA LEY 30/1992-4/1999 Y SU TRASCENDENCIA PARA LOS DERECHOS DE LOS CIUDADANOS Y PARA LA MATERIALIZACIÓN DEL SISTEMA ADMINISTRATIVO. III. EL PRECEDENTE DE LA LEGISLACIÓN DE RÉGIMEN LOCAL EN EL ÁMBITO DE LOS ARCHIVOS Y SU RELATIVIZACIÓN. IV. LA INTERCONEXIÓN TELEMÁTICA DE ARCHIVOS, REGISTROS Y PROCEDIMIENTO EN FUNCIÓN DE LOS DERECHOS DEL CIUDADANO ANTE LAS ADMINISTRACIONES PÚBLICAS. V. DE LA SECRETARÍA MUNICIPAL AL RESPONSABLE DE CADA PROCEDIMIENTO, COMO REFERENCIA OBJETIVA Y SUBJETIVA, QUE REQUIERE LA ARTICULACIÓN DE ARCHIVOS, REGISTROS Y SECRETARÍA. VI. LA SUSTITUCIÓN DE LA METODOLOGÍA DE LEGISLACIÓN BÁSICA, PARA LA CREACIÓN DE UN SISTEMA INTERCONECTADO DE REGISTROS Y ARCHIVOS ADMINISTRATIVOS, POR EL ACUERDO CONVENCIONAL DE LAS COMUNIDADES AUTÓNOMAS Y DE LAS ENTIDADES LOCALES. VII. LA INCORPORACIÓN DEL PRINCIPIO DE BUENA ADMINISTRACIÓN POR EL TRATADO POR EL QUE SE ESTABLECE UNA CONSTITUCIÓN PARA EUROPA COMO REQUERIMIENTO PARA LA RECREACIÓN DEL SISTEMA ADMINISTRATIVO DEL ESTADO DESCENTRALIZADO ESPAÑOL, DESDE LA REFERENCIA BASILAR DE LA ADMINISTRACIÓN LOCAL.
\end{abstract}

\section{INTRODUCCIÓN}

La afortunada descripción que realiza el artículo 137 de la Constitución de la estructura territorial del Estado, mediante la armónica secuencia de municipios, provincias y Comunidades Autónomas, con el resultado de delimitar el conjunto espacial del Estado ${ }^{1}$, no ha tenido, hasta el momento, consecuencias para el ciudadano en la materialización de un sistema organizativo del conjunto institucional del Estado, en el que aquél pueda sentirse integrado, de modo que el ciudadano del Estado descentralizado se ve obligado a vagar entre las mónadas administrativas en las que se ha fragmentado el Estado centralizado, sin que el sistema administrativo repare la aflictiva condición del ciudadano en el deslabazado conjunto interadministativo,

\footnotetext{
${ }^{1}$ El significado del precepto es objeto de la atención del profesor Lorenzo MarTín-REToRTILLo en el prólogo a Antonio Fanlo LoRAs, Fundamentos constitucionales de la autonomía local, Centro de Estudios Constitucionales, Madrid 1990, p. 27.
} 
condicionado por la insularidad en la que se posicionan las distintas administraciones y que, entre otros condicionantes para el ciudadano, le imponen la carga de actuar de correo entre ellas².

\section{LAS APORTACIONES SISTÉMICAS DE LOS ARTÍCULOS 37, 38 y 45 DE LA LEY 30/1992-4/1999 Y SU TRASCENDENCIA PARA LOS DERECHOS DE LOS CIUDADANOS Y PARA LA MATERIALIZACIÓN DEL SISTEMA ADMINISTRATIVO}

El intencionalmente asistemático artículo 35 de la Ley 30/1992, de Régimen Jurídico de las Administraciones públicas al enunciar los derechos de los ciudadanos ante sus Administraciones, carente de modificaciones en la revisión realizada por la Ley 4/1999, está acompañado de un instrumental que sintetiza las aportaciones de la Ley: sujeción de los procedimientos a preciso plazo temporal de tramitación, positivización de los efectos de las pretensiones de los ciudadanos ante las Administraciones cuando concurre inactividad administrativa, y el control de la documentación administrativa mediante la secuencia instrumental de registros y archivos administrativos, con la gestión documental realizada por medios electrónicos, informáticos y telemáticos.

Lamentables han sido los excesos que han desvirtuado los plazos administrativos previstos por la Ley 30/1992- 4/1999, para la resolución de los procedimientos administrativos, y que en muchos procedimientos han multiplicado por varios dígitos las iniciales previsiones de la paradójicamente calificada como Ley de Procedimiento Común, excesos avalados mediante la utilización de las Leyes de acompañamientos a los Presupuestos Generales del Estado, aprobadas por las Cortes Generales y por los Parlamentos autonómicos y que han hecho saltar, año tras año los plazos ${ }^{3}$.

\footnotetext{
${ }^{2}$ Sigue siendo válida la observación realizada en la Comisión de Redes Informáticas del Senado, 19981999: «Los ciudadanos ... perciben claramente como un abuso cierto un mal servicio ... que sean ellos mismos quienes deben hacer de correo entre los diferentes servicios de la Administración». Vid. Comparecencia de Carlos Marín Delgado, Delegado de la Sección de Informática del Consejo General del Notariado, Diario de Sesiones del Senado de 1 de junio de 1998, nº. 295, p. 3.

${ }^{3}$ Como ejemplo, la Ley 53/2002, de Medidas Fiscales, Administrativas y de Orden Social, eleva a 12 meses el periodo temporal para notificar las resoluciones de procedimiento de extinción de ocupaciones de dominio público y las sanciones administrativas en materia de costas marítimas (Capítulo VIII, artículo 94). Remito a la preocupación mostrada, sobre los contenidos perturbadores de las leyes de acompañamiento por el profesor García de Enterria: Justicia y seguridad jurídica en un mundo de leyes desbocadas, Cuadernos Civitas, Madrid 1999, problemática que parece asumir el Gobierno de la Nación con la voluntad de neutralizar la Ley de Medidas, pero que ha carecido del oportuno acompañamiento autonómico. Al respecto: La Comunidad Autónoma del Principado de Asturias aporta la Ley $7 / 2005$, de 29 de diciembre, de medidas presupuestarias, administrativas y tributarias de acompañamiento a los Presupuestos Generales para 2006; la Comunidad Autónoma de Cataluña, la Ley 21/2005, de 29 de diciembre, de medidas financieras; la Comunidad Autónoma de las Illes Balears, la Ley 13/
} 
El reduccionismo a la historiografía que propició para los Archivos el largo periodo temporal 1936-1992, es corregido por el artículo 37 de la Ley 30/1992, que obliga a volver a utilizar el término archivo administrativo - como referencia administrativa inexcusable para la racionalidad procedimental, la materialización de los derechos de los ciudadanos y para el sucesivo rigor historiográfico-y que son integrados en la secuencia de los registros administrativos y de la utilización de las técnicas electrónicas, informáticas y telemáticas y, con ello se recupera, desde las bases del régimen jurídico de las Administraciones públicas, los testimonios residuales que en el ámbito de la Administración local habían pasado desapercibidos al autoritarismo político.

La secuencia en la regulación de los archivos, registros y técnicas telemáticas, contenida en los artículos 37, 38 y 45 de la Ley 30/1992 aportan, con la condición de bases de régimen jurídico de las Administraciones públicas y elementos determinantes en las premisas que pretenden configurar el procedimiento común, los instrumentos necesarios para la interconexión documental administrativa como premisa para poder hacer operativa la exigencia procedimental de resolver en tiempo y forma y para la coherente articulación del sistema administrativo del Estado descentralizado.

En la recuperación de los archivos administrativos y su interconexión con los registros administrativos y con la metodología de las tecnologías electrónicas, informáticas y telemáticas, sustrayendo la documentación pública de la instrumentalizadora clave historicista, en la que se situó en la postguerra civil, está particularizado el embrión de la necesaria integración organizativa y operativa del conjunto institucional administrativo al servicio de un ciudadano, al que la Unión Europea le garantiza la libertad de movimientos en el entramado económico, laboral y profesional de los Estados comunitarios, pero que, en la realidad del conjunto institucional del Estado descentralizado español, no es capaz de tramitar un documento administrativo que requiera la intervención de las instancias administrativas descentralizadas sin aportar el directo impulso personal de la presentación personal, directa o por representante, ante la multiplicidad de instancias administrativas intervinientes.

2005, de 27 de diciembre, de medidas tributarias y administrativas; la Comunidad Autónoma de Castilla y León, la Ley 13/2005, de 27 de diciembre, de medidas financieras; la Comunidad Foral de Navarra, la Ley Foral 19/2005, de 29 de diciembre, de modificación de diversos impuestos y otras medidas tributarias; la Comunidad Autónoma de Cantabria, la Ley 6/2005, de 26 de diciembre, de Medidas Administrativas y Fiscales para la Comunidad Autónoma de Cantabria para el año 2006; la Comunidad Autónoma de La Rioja, la Ley 13/2005, de 16 de diciembre, de medidas fiscales y administrativas para el año 2006. La ampliación de los plazos administrativos previstos para resolver y notificar no es privativo de las Leyes de acompañamiento, como muestra, en la Comunidad Autónoma de Andalucía, la concesión de emisoras de Frecuencia Modulada, privadas o a Coporaciones locales, cuenta con el plazo de 24 meses y la autorización para el aprovechamiento, modificación o ampliación de estructuras subterráneas con un plazo de 36 meses y, en el punto intermedio, el plazo previsto para las instalaciones eléctricas de suministro público es de 18 meses (Ley 9/2001, de 12 de julio). 
Los valladares que condicionaron la proyección operativa de Ley de Procedimiento Administrativo de 1958 y que, de modo específico, soslayaron, la incorporación de los archivos administrativos como elemento ineludible para el rigor de la tramitación de los procedimientos administrativos de la entonces Administración centralizada ${ }^{4}$, se reproduce en la tardía revisión de la concreción del procedimiento administrativo común de las Administraciones del Estado descentralizado, sin reparar en el carácter básico de los registros y archivos administrativos, y sin cuya coherente articulación son menoscabados los derechos de los ciudadanos ante las Administraciones públicas y la igualdad de posición de estos ante ellas con independencia de su ubicación.

No se repara en la incoherente infrautilización de los medios electrónicos, informáticos y telemáticos de las Administraciones públicas que, con la excepción de las áreas sensibles de seguridad pública y tributación económica, no pasan de ser identificados con máquinas de escribir sin plantearse la interconexión en red ni en la misma dependencia administrativa, en elocuente contraste con las utilidades que las redes telemáticas aportan al sector privado y, por efecto inducido, a la mayor racionalidad de la gestión de los asuntos diarios de los ciudadanos en el ámbito privado.

La neutralización política del profesor López Rodó, en su deseo de incorporar a la Ley de Procedimiento Administrativo de 1958, la integración de los archivos en el procedimiento administrativo, es ilustrativa del oculto sentido político y administrativo de los archivos, referentes organizativos y procedimentales del régimen jurídico de las Administraciones públicas y del ejercicio de los derechos de los ciudadanos ante ellas y a través de ellas.

La Ley 30/1992, en su artículo 37, reintegra al sistema administrativo y al ordenamiento jurídico los archivos e incorpora, al régimen jurídico de las Administraciones y al procedimiento administrativo, el elemental punto de referencia del buen orden documental, en garantía del buen hacer administrativo y, con ello, contribuye a salvar la cínica actitud del precedente régimen autocrático: mitificar los archivos históricos en simultaneidad con su voluntad de hacer desaparecer los archivos administrativos, con el perverso efecto del correspondiente vacío para los archivos históricos del Estado autocrático, difuminados en las desordenadas transferencias de fondos de Sindicatos y Movimiento a la Administración General del Estado y con el agregado de diluir los Archivos de la Jefatura del Estado en una fundación privada, criterio que demanda ser oportunamente subsanado con la incorporación al Sistema de Archivos Estatales, en lógica secuencia con la reintegración a la

\footnotetext{
${ }^{4}$ Al respecto, y con una ejemplar discreción en sus enunciados y contenidos, los artículos de Javier LASSO DE LA Vega JimÉneZ Placer, «Necesidad de aplicar un sistema orgánico a la ordenación de los archivos administrativos», Revista de Administración Pública nº 28 (1959), pp. 273-302, Luis SÁNCHEZ BELDA, «Un lapsus en la Ley de Procedimiento Administrativo (sobre archivos)», Documentación Administrativa $\mathrm{n}^{\circ}$. 62-63 (1963), pp. 68-73, y Carmen PESCADOR DEL HoYo, «Un problema de la Administración sin resolver (sobre archivos)», Documentación Administrativa nº 77 (1964), pp. 85-101.
} 
Generalidad de Cataluña de los fondos documentales contenidos en el Archivo Histórico de la Guerra Civil 5 .

Con cierto retraso temporal en relación con las premisas del nuevo sistema institucional de la Constitución de 1978, los archivos son situados, por la Ley 30/1992, en dos determinantes relaciones triangulares: la relación tripartita de archivos, registros administrativos y derechos de los ciudadanos, y la interconexión de tres vectores: archivos, registros e informatización administrativa, con el objetivo de producir el resultado de que las Administraciones resuelvan, en los tiempos y en las formas preestablecidas, los procedimientos administrativos, con la voluntad de conducir a la noche de los tiempos la autocrática desviación metodológica del calificado como «silencio administrativo» y los abusivos plazos que las Administraciones se autoconceden para resolver los procedimientos.

El carácter básico de la regulación de los archivos, su interconexión con los registros, y la interdependencia de ambos con la gestión del procedimiento administrativo mediante la integración telemática de las unidades administrativas y el sustrato básico de todo ello en los derechos de los ciudadanos ante las Administraciones públicas, tiene en la pluralidad de las Administraciones públicas del Estado descentralizado, el punto de referencia basilar de los archivos y registros, componentes objetivos estructurantes de las relaciones interadministrativas del Estado social, democrático y de Derecho.

La reforma de la Ley 30/1992 por la Ley 4/1999 y la profundización por ésta de las líneas de garantía diseñadas por la primera, permiten calificar el conjunto legal resultante como un conjunto normativo cuya autoridad avala el implícito consenso político de la sucesión de distintas mayorías políticas parlamentarias.

\section{EL PRECEDENTE DE LA LEGISLACIÓN DE RÉGIMEN LOCAL EN EL ÁMBITO DE LOS ARCHIVOS Y SU RELATIVIZACIÓN}

El elevado numero de municipios que articulan las provincias españolas, requirió, y requiere, la articulación organizativa y operativa en los ámbitos institucional y ordinamental, de modo que las bases organizativas y procedimentales vertebraran la pluralidad.

Los Cuerpos Nacionales de Administración Local, la estructura operativa de archivo y registro y las precisiones normativas sobre la documenta-

\footnotetext{
${ }^{5}$ Ley 21/2005, de 17 de noviembre, de restitución a la Generalidad de Cataluña de los documentos incautados con motivo de la Guerra Civil custodiados en el Archivo General de la Guerra Civil Española y de creación del Centro Documental de la Memoria Histórica.
} 
ción administrativa municipal y su ordenación en la precisa figura del expediente, ha sido la equilibrada instrumentación que ha dispuesto la legislación local.

El Reglamento de Organización y Funcionamiento de las Corporaciones Locales de 1986 ofrece síntesis de la estructura organizativa y operativa descrita, como muestra de la supervivencia en el ámbito local de lo perdido en la Administración General del Estado y de lo no recuperado en las Administraciones autonómicas, por efecto inducido de la copia del modelo central. Expresivo es el artículo 148 del Reglamento de Organización:

«Las entidades locales deben velar por la custodia, ordenación, clasificación y catalogación de los documentos y expedientes...».

En el precepto trascrito está contenida una obligación para los entes locales, en la que se implica la función de secretaría y las funciones de registro y archivo, como inexcusables funciones garantizadoras de la correcta gestión de la documentación municipal en la satisfactoria prestación de los servicios y en la resolución de los procedimientos administrativos iniciados por los vecinos.

La específica consideración en el precepto de la actividad de catalogación de documentos y expedientes, remite a la función archivística, objeto de la actividad profesional del prestigioso, instrumentalizado y relegado Cuerpo Facultativo de Archivos, Bibliotecas y Arqueólogos, con su complemento en el Cuerpo de Ayudantes de Archivos, Bibliotecas y Museos, y la ausencia de precisión al archivero, como especifica referencia funcionarial, se integra en la atención del Reglamento de Organización al conjunto de municipios, con la dificultad de que todos los municipios puedan reproducir el mismo esquema funcionarial sin las precisiones que, en función de población y medios presupuestarios, dispone el Reglamento de Funcionarios.

La obligación de velar por la custodia, ordenación, clasificación y catalogación de los documentos y expedientes, está instrumentada por la precisa regulación que la legislación local ha realizado y realiza del registro de documentos, con pormenorizada atención a la entrada, inscripción, clasificación, distribución entre las distintas oficinas, y salida de documentos; a la función del secretario, del responsable del registro y de la interrelación con las secciones o negociados, y con oportuna atención a la entrega de recibo gratuito a toda persona que presente escrito en el registro y a las certificaciones de los asientos registrales autorizadas por el secretario.

La detallada regulación de los expedientes en el Reglamento de Organización, Funcionamiento y Régimen Jurídico de las Entidades Locales, materializa una específica singularidad de la legislación local, que requiere reparar en la carencia de utilización de este preciso término por la legislación de procedimiento administrativo estatal, con la preocupante desatención al 
concepto y a las implicaciones del expediente, conforme al preciso tenor literal del artículo 164.1 del referido Reglamento:

«... el conjunto ordenado de documentos y actuaciones que sirven de antecedente y fundamento a la resolución administrativa, así como las diligencias encaminadas a ejecutarla».

La práctica de las entidades locales en la ordenación de documentos y actuaciones puede ser calificada como la reserva de buenas prácticas administrativas, que radican en la Administración local, y que pueden proyectarse sobre el resto de las Administraciones, en la necesaria recuperación, por éstas, de las distorsiones autoritarias que les han afectado de modo directo $\mathrm{o}$ inducido.

\section{LA INTERCONEXIÓN TELEMÁTICA DE ARCHIVOS, REGISTROS Y PROCEDIMIENTO EN FUNCIÓN DE LOS DERECHOS DEL CIUDADANO ANTE LAS ADMINISTRACIONES PÚBLICAS}

La interconexión documental de las Administraciones del Estado descentralizado es una exigencia estructural de las instituciones del propio Estado y un requerimiento institucional para la efectiva materialización de los derechos de los ciudadanos ante las Administraciones públicas.

El Estado descentralizado requiere recuperar el momento unitivo, en función de los ciudadanos, y de los procedimientos administrativos que interconectan a las distintas administraciones del Estado descentralizado, con la misma naturalidad que el ciudadano en sus desplazamientos transita por distintos municipios, provincias y comunidades autónomas, materializando la libre iniciativa económica o el libre ejercicio de actividades laborales o profesionales.

La integración organizativa de las distintas Administraciones con la finalidad de materializar el derecho del ciudadano a recuperar la unidad del Estado desde cualquiera de ellas, tiene particular importancia para la Administración local, para cada una de las unidades municipales, donde, por razón de vecindad o por razón de residencia, el registro municipal de documentos, puede ser la referencia más inmediata para conectar con cualquier otra dependencia administrativa del Estado, o como referente para cualquier trámite ante cualquier instancia comunitaria europea, en el ejercicio de derechos como ciudadano comunitario, bien como proyección de las referencias administrativa de ciudadano español o bien como proyección de residente comunitario en España en sus relaciones con las instituciones comunitarias o con las instancias administrativas del Estado comunitario del que es nacional. 
Retornando al ordenamiento nacional, la interrelación de registro y archivos es la premisa para poder materializar la sustantiva aportación de la Ley 30/ 1992-4/1999: la resolución expresa de los procedimientos iniciados por los ciudadanos ante las Administraciones públicas, en el plazo que tienen predeterminado, y la línea tendencial a considerar resueltos, en sentido favorable a las pretensiones de los solicitantes, cuando los procedimientos no hayan sido resueltos de modo expreso en el plazo preestablecido.

Con la Ley 30/1992-4/1999, y sus específicas alternativas de rigor en el tratamiento de las documentación pública, las Administraciones públicas del Estado descentralizado no logran nada excepcional: se limitan a homologarse, con el buen orden en la documentación que el sector privado practica, en el tratamiento de su documentación administrativa, por su propia seguridad jurídica y por las exigencias que las Administraciones públicas imponen, muy en particular, en el ámbito recaudatorio.

La informatización de los procedimientos y la interconexión entre las distintas Administraciones del Estado requerida por la Ley 30/1992-4/1999, se limita a conectar con las buenas prácticas que el autoritarismo político hizo perder a las acreditadas prácticas documentales y archivísticas españolas hasta la Guerra Civil y desde ella hasta los mandatos, aún pendientes de cumplimiento, de los referidos textos legales.

\section{DE LA SECRETARÍA MUNICIPAL AL RESPONSABLE DE CADA PROCEDIMIENTO, COMO REFERENCIA OB- JETIVA Y SUBJETIVA, QUE REQUIERE LA ARTICULA- CIÓN DE ARCHIVOS, REGISTROS Y SECRETARÍA}

Las unidades administrativas de Registro y Archivo han tenido la referencia funcional de la Secretaría, en calidad de vertebradora e impulsora de la tramitación de los procedimientos por los responsables de las unidades administrativas que en cada caso correspondan, dinámica clásica en los esquemas organizativos, que ha tenido, en el ámbito de la Administración, la figura clave de la Secretaría General.

La Ley 30/1992-4/1999 no integra la figura de la Secretaría, aunque, de modo inevitable, tiene que particularizar en precisos referentes subjetivos la exigencia de responsabilidad por la tramitación de los procedimientos y, como inevitable corolario de Registro y Archivo, está la unidad administrativa que, por razón de su competencia, asume los procedimientos que le correspondan por razón de su materia.

Contribuyen a precisar el responsable de cada procedimiento, las previsiones del artículo 74 de la Ley 30/1992, relativa al orden de incoación de los procedimientos, con la secuencia del artículo 78, al regular los actos de 
instrucción, y las correlaciones derivadas de los derechos de los ciudadanos ante las Administraciones públicas, expresadas en los contenidos del artículo 35,b): el derecho del ciudadano a identificar al responsable del procedimiento, sin olvidar el primero de los derechos enunciado en la secuencia del artículo 35, al particularizar en el punto a): el derecho del ciudadano a conocer la tramitación del procedimiento que, en su sencillo enunciado, implica personificar los procedimientos, tanto en clave de ciudadano interesado como en clave de funcionario encargado, y precisar los distintos trámites con similar precisión a lo que las agencias de mensajería practican para saber el preciso estado y situación del envío pendiente de entrega.

El esquema formal descrito no está exento de problemas, de modo que el éxito previsible de la agencia de mensajería-cuya documentación empresarial podrá ser supervisada por las Administraciones territoriales, la central, la autonómica y la local- ante el cliente que demanda información relativa a un envío, puede carecer de equivalencia con la petición de un ciudadano relativa al estado del procedimiento que le afecta, en detrimento del buen fin de los procedimientos administrativos, en menoscabo del prestigio público y en menosprecio de los derechos ciudadanos.

La desaparición del término Secretaría en la legislación administrativa y la dilución de la Secretaría General de Ayuntamientos y Diputaciones por el efecto combinado de las modificaciones del régimen de los Cuerpos Nacionales de Administración Local en $1993^{6}$ y $2003^{7}$, ha generado problemas bien conocidos para el buen orden documental, procedimental y archivístico de las Administraciones: la central y la autonómica, ámbitos en los que las secretarías han derivado a secretarías técnicas, y en la Administración local, donde la Secretaría General como punto clave de la organización municipal vinculada por el principio de legalidad, ha mutado en asesoría jurídica ${ }^{8}$.

La coherencia de la Ley 30/1992-4/1999 quiebra por la ignorancia de la figura institucional de la Secretaría, como referente organizativo inexcusa-

\footnotetext{
${ }^{6}$ La Ley 10/1993, de modificación de puestos de trabajo reservados a Funcionarios de Administración Local con Habilitación Nacional, en artículo 2, permite sustituir el concurso por la libre designación para los Secretarios que asuman puestos en Diputaciones, Cabildos, Consejos Insulares, Ayuntamientos capitales de Comunidad Autónoma o provinciales, y municipios de población superior a cien mil habitantes con nivel 30 de complemento. La libre designación afecta también a los Interventores cuando concurran las circunstancias señaladas y el presupuesto de la Corporación supere los tres mil millones de pesetas.

${ }^{7}$ El artículo 122.5 de la Ley 57/2003, de modernización del Gobierno Local, incorpora la libre designación por el Alcalde del Secretario General del Pleno, reservado a Funcionarios de Administración Local con Habilitación Nacional y cuyo rango está condicionado por las normas orgánicas que regulan cada Pleno.

${ }^{8}$ El artículo 129 de la Ley 57/2003, regula la Asesoría Jurídica y la desvincula del cuerpo de Secretarios con Habilitación Nacional, al disponer que su titular, para el que se requiere la posesión del título de licenciado en Derecho, puede ser Funcionario de Administración Local con Habilitación Nacional o bien funcionario de carrera del Estado, de las Comunidades Autónomas o de las Entidades Locales.
} 
ble para el Registro y el Archivo, en el que, en último extremo, subyace la figura del expediente administrativo, que ofrece seguridad jurídica para la vía procedimental y es la premisa para el sucesivo control jurisdiccional contencioso administrativo.

La potenciación y estricta profesionalización en el ámbito privado de las funciones de Registro-Archivo-Secretaría contrasta con la desarmónica recepción en la Ley 30/1992-4/1999 de Registro-Archivo, sin la referencia organizativa y operativa de la Secretaría, y con la relativización de la única secretaría que sobrevivió al autoritarismo político: la Secretaria General de Ayuntamientos y Diputaciones, condicionada en su funcionalidad por los elementos de discrecionalidad que inició la Ley de 10/1993 y que culmina la Ley de 57/2003, en cuya nueva configuración de la Junta de Gobierno de los Ayuntamientos de Gran Población la función de Secretaría es desglosada de los funcionarios de Cuerpo de Habilitación Nacional que se limitan a ser órgano de apoyo al concejal al que se atribuye por el alcalde la condición de secretario de la Junta de Gobierno Local ${ }^{9}$, en severo detrimento del ejercicio profesional de la fe pública y de la necesaria coherencia en la tramitación de los procedimientos administrativos.

\section{LA SUSTITUCIÓN DE LA METODOLOGÍA DE LEGISLACIÓN BÁSICA, PARA LA CREACIÓN DE UN SISTEMA INTERCONECTADO DE REGISTROS Y ARCHIVOS ADMINISTRATIVOS, POR EL ACUERDO CONVENCIONAL DE LAS COMUNIDADES AUTÓNOMAS Y DE LAS ENTIDADES LOCALES}

Los efectos operativos de las previsiones del artículo 45 de la Ley 30/1992, sobre la aplicación de las técnicas electrónicas, informáticas y telemáticas a los procedimientos administrativas, fueron prácticamente nulos hasta la Resolución de 7 de abril de 1997, de la Secretaría de Estado para la Administración Pública ${ }^{10}$, por la que se dispone la publicación del Acuerdo del Con-

\footnotetext{
9 Artículo 126.4 de la Ley 57/2003, al regular las Juntas de Gobierno Local en el régimen de organización de los municipios de gran población.

${ }^{10}$ El Real Decreto 263/1996, se limita a regular las técnicas electrónicas, informáticas y telemáticas en el estricto ámbito de la propia Administración General del Estado; la Resolución de la Secretaría de Estado para la Administración Pública de 28 de febrero de 1996, se limita a regular los Convenios con la Administración Local; el Real Decreto 772/1999 mantiene el exclusivo referente de la Administración General del Estado en la regulación de los Registros administrativos, y las modificaciones del Real Decreto 263/1996 por el Real Decreto 209/2003, se mantiene en el ámbito estricto de la Administración General del Estado, al regular los registros y las notificaciones telemáticas, así como la utilización de medios telemáticos para la sustitución de la aportación de certificados por los ciudadanos.

Con referencia en otros Poderes del Estado y, con independencia de la aproblemática gestión del Congreso, Senado y Tribunal Constitucional, el Poder Judicial está condicionado en su gestión por dos referencias: la relativa a la publicación de sus sentencias y la gestión de la Secretaría Judicial. Las Sen-
} 
sejo de Ministros de 4 de abril de 1997, para la progresiva implantación de un sistema intercomunicado de Registros entre la Administración General del Estado, las Administraciones de las Comunidades Autónomas y las Entidades que integran la Administración Local.

La proyección del referido Acuerdo del Consejo de Ministros ha estado condicionado, en sus resultados, por la doble incidencia del distanciamiento de los Gobiernos autonómicos nacionalistas y de la voluntad de diferenciación política, de tal modo que, los Convenios previstos por el Acuerdo, sólo han sido formalizados por diez Comunidades Autónomas y están segregadas del sistema intercomunicado de Registros siete Comunidades Autónomas y las dos Ciudades Autónomas.

Los resultados a nivel municipal de los Convenios a formalizar por cada Ayuntamiento con el Ministerio de Administraciones Públicas sólo ofrecen los resultados razonables de la Comunidad Autónoma de Extremadura y de la Comunidad Autónoma de Madrid. Sin poder entrar en el análisis pormenorizado de los datos autonómicos, provinciales y municipales, objeto del proyecto calificado como de «Ventanilla Única para las Administraciones Públicas ${ }^{11}$, parece obligado resaltar que el respeto mostrado por la Administración

tencias están condicionadas en su publicación por los distintos sistemas informáticos arbitrados en el ámbito de la «Administración de la Administración de Justicia» por las correlativas Comunidades Autónomas y que, sin perjuicio de los problemas que genera la compatibilidad de los sistemas entre los distintos Tribunales Superiores de Justicia, tiene el referente documental del Centro de Documentación Judicial mediante acuerdos del Pleno del Consejo General del Poder Judicial (Acuerdos de 7 de mayo de 1997, por el que se aprueba el Reglamento 1/1997, del Centro de Documentación Judicial, y de 18 de junio de 1997 y 9 de abril de 2003, por los que se aprueban las Instrucciones para la remisión de las Resoluciones Judiciales). Como es bien conocido, la publicación de las Sentencias es objeto de la atención de editoriales privadas mediante la adquisición al CENDOJ, con el efecto inducido de elementos aleatorios en la selección, en detrimento de la función pública para autentificar la Doctrina Judicial. En relación con la gestión de los Procesos, la reforma de la Ley Orgánica del Poder Judicial, por la Ley 19/2003, al regular la Oficina Judicial, incorpora, en su Libro V, esperanzadoras posibilidades para adecuar la estructura organizativa y operativa de la Administración de Justicia a los parámetros de eficacia mediante la integración de la telemática en los procesos judicial, con la dirección de la Secretaría Judicial y la activa colaboración de Letrados y Procuradores con los Colegios Profesionales que los representan.

${ }^{11}$ Con proyección en las Comunidades Autónomas de Canarias (Convenio de 10 de junio de 1998), Cataluña (Convenio de 17 de mayo de 1997), Castilla y León (Convenio de 12 de mayo de 1997), Castilla-La Mancha (Convenio de 8 de julio de 1998), Extremadura (Convenio de 10 de junio de 1997), Galicia (Convenio de 21 de junio de 1997), Illes Balears (Convenio de 21 de julio de 1998), Madrid (Convenio de 21 de mayo de 1997), Murcia (Convenio de 7 de noviembre de 1998) y Comunidad Valenciana (Convenio de 20 de mayo de 1997).

La efectiva articulación de la que puede y debe ser calificada como Red Telemática de las Administraciones Públicas del Estado Español, a integrar en la Red Telemática de los Estados Miembros de la Comunidad Europea, está lamentablemente condicionada por el lapso de tiempo transcurrido en las firmas de los Convenios con las Comunidades Autónomas que los han suscrito (mayo de 1997-noviembre 1998), así como por el conjunto territorial afectado por las Comunidades Autónomas que aún quedan pendientes de integración (Andalucía, Aragón, Asturias, Cantabria, Navarra, País Vasco, La Rioja, más la Ciudades Autónomas de Ceuta y Melilla) y, en consecuencia, el reducido número de municipios implicados, con particular incidencia negativa en las Comunidades carentes de Convenio, circunstancias que permiten detectar graves insuficiencias, con la ejemplar excepción institucional de Extremadura y de sus municipios. El número de municipios con convenio, desglosados por provincias tiene las 
General del Estado para con las Comunidades Autónomas, Diputaciones Provinciales y Ayuntamientos, ofreciendo la fórmula de Convenio a formalizar con el Ministerio de Administraciones Públicas, no permite ignorar que estamos ante una opción de unívoco carácter institucional, que debiera ser identificada con las Bases del Régimen Jurídico de las Administraciones Públicas o con parte sustantiva del Procedimiento Administrativo Común de las Administraciones del Estado.

La obligada formalización de los Convenios pendientes y la detallada concreción de su contenido, incorporando las creativas iniciativas de Comunidades Autónomas, Diputaciones Provinciales, Ayuntamientos, sin olvidar Cabildos y Consejos Insulares, ni Comarcas, Mancomunidades y Consorcios, está requerida por afectar al núcleo de los derechos de los ciudadanos, quienes tenemos el derecho de usar las vías de acceso a las Administraciones Públicas sin el condicionante de la ancestral ventanilla, en algunos casos, sustituida por mostradores más abiertos y que, incluso, pueden llegar a incorporar, en muy determinados casos, el más digno referente de la interlocución en mesa de despacho personalizada, y a poder llegar materializar de modo efectivo el medio de relación con la Administración, conforme a la previsión habilitada por la Ley 30/1992 en el inicio de los procedimientos administrativos a instancia de parte ${ }^{12}$.

En la dinámica de las relaciones de los ciudadanos con las distintas unidades administrativas, los ciudadanos tenemos que materializar el elemental derecho de dejar de ser correos gratuitos ante las muy heterogéneas y dispersas unidades administrativas del Estado descentralizado, por añadidura, supeditadas en su funcionamiento a horarios configurados en directa correlación con dinámicas sindicales, que requieren integrar la incertidumbre de fiestas locales, regionales, provinciales y nacionales, en un conjunto de referencias cruzadas aportadas por cada uno de las unidades administrativas que puedan intervenir en un procedimiento.

Es necesario corregir la agraviante condición del ciudadano, portador de escritos ante la multiplicidad de unidades administrativas, con la que coincide la situación del ciudadano obligado a reptar entre deteriorados y desatendidos tabloides, con el propósito de identificar apellidos, numerales de identidad o domicilio, que no excluye, con el mismo propósito de «encon-

siguiente referencias: Alava: ninguno; Albacete: 11; Alicante: 22; Almería: 13; Asturias: 4; Avila: 17; Badajoz: 116; Barcelona 38; Burgos: 12; Cáceres: 103; Cádiz: 16; Cantabria: 11; Castellón: 8; Ceuta: sin convenio; A Coruña: 32; Ciudad Real: 24; Córdoba: 13; Cuenca: 13; Granada: 8; Guadalajara: 4; Guipúzcoa: 1; Huelva: 8; Islas Baleares: 3; Jaén: 8; León: 21; Lugo:24; Madrid 23; Málaga: 7; Meli1la: sin convenio; Navarra: 4; Murcia: 9; Ourense: 25; Palencia: 10; Las Palmas de Gran Canaria: 12; Pontevedra: 24; La Rioja: 2; Salamanca: 15; Santa Cruz de Tenerife: 27; Segovia: 23; Sevilla: 13; Teruel 8; Toledo: 21; Valencia: 29; Vizcaya: 1. Datos obtenidos de la página Web del Ministerio de Administraciones Públicas: www.isgap.map.es/BASISCGI/.

12 Artículo 70.1,a) Ley 30/1992-4/1999. 
trarse», la actividad, digital, como consecuencia del ejercicio de colocar el dedo índice en listados, que pueden ser alternativos, de Boletines y Diarios Oficiales, de difícil localización y consulta.

Situaciones como las descritas están en conflicto con la actividad profesional, la dinámica familiar, menoscaba la utilización razonable del tiempo, y la oportuna corrección tiene su referente objetivo y su inicio en los Convenios interadministrativos a formalizar en el marco del referido Acuerdo del Consejo de Ministros de 4 de abril de 1997, mediante la conexión interadministrativa de Registros, que necesariamente deberá incorporar la alternativa de Internet, en calidad de medio más razonable, por su economía, accesibilidad y seguridad, para la interlocución personalizada del ciudadano con las Administraciones Públicas.

Necesario es, desde las exigencias derivadas del cumplimiento de las Bases del Régimen Jurídico de las Administraciones Públicas, neutralizar el agravio que sufre el vecino de cualquiera de los municipios, aún desasistidos por su Comunidad Autónoma, su Diputación Provincial y su Ayuntamiento, en relación con el afortunado vecino, objeto de la inteligente actuación de todas sus Administraciones territoriales, concertadas para ofertarle la red informatizada de Registros interadministrativos, para satisfacer, del mejor modo, forma y tiempo, la tramitación de cualquier asunto de su interés ante el conjunto de las Administraciones Públicas, incluida la terminal administrativa de los asuntos que requieran la intervención de las Comunidades Europeas.

Obligado es apreciar la incongruencia que provoca, en clave de respeto a los elementales requerimientos del Procedimiento Administrativo Común, la ausencia de interconexión informatizada de Registros administrativos en el conjunto de las Administraciones del Estado, cuando las reglas del procedimiento tienen la concreción de unos períodos, concebidos como máximos para resolver, y que debieran de agregar la sensata práctica común de hacer mínimos los periodos temporales máximos de resolución, premisa que requiere el llegar a obviar, por las Administraciones del siglo XXI, el sistema de transporte de sus documentos por ruedas de pequeño radio con fricción sobre la convencional superficie de asfalto y que requiere reparar en que, el más evolucionado sistema de transporte marítimo o aéreo, no logra operar con la inmediatividad, economía y seguridad de la transmisión electrónica de los documentos entre Administraciones a través del sistema informatizado e interconectado de Registros administrativos.

Pertinente es recordar a las Comunidades Autónomas, Diputaciones Provinciales, Cabildos, Consejos Insulares, Comarcas, Mancomunidades, Consorcios y Ayuntamientos, que tienen pendiente la formalización del Convenio previsto por el Acuerdo del Consejo de Ministros de 4 de abril de 1997, que han incumplido las Bases del Régimen Jurídico de las Administraciones Públicas y el Procedimiento Administrativo Común, vulnerando, en consecuencia, una Ley que materializó el consenso político de las Cortes Genera- 
les en la reforma administrativa iniciada por la Ley 30/1992 y perfeccionada y profundizada por la Ley 4/1999.

En la necesaria conclusión de la red telemática del conjunto institucional de las Administraciones del Estado Español, o Reino de España, es preciso no identificar la materialización de los convenios con la autonomía de la voluntad de las personas jurídicas, Comunidades Autónomas o Corporaciones Locales implicadas; el tenor literal del artículo 38.4. in fine, en el texto de la Ley 30/1992, enriquecido por la Ley 4/199913, aporta la determinación del carácter imperativo de los convenios de colaboración, vinculados al objetivo, conforme al cual, «se establecerán sistemas de intercomunicación y coordinación de registros», sistemas que deben cumplir con la finalidad de que «garanticen su compatibilidad informática y la transmisión telemática de los asientos registrales y de las solicitudes, escritos, comunicaciones y documentos que se presenten en cualquiera de los registros».

En el contexto de la inactividad administrativa en el desarrollo de la interconexión informatizada de las Administraciones públicas, en el que no puede pasar desapercibido el dato de la regulación de los registros telemáticos por la Ley de Medidas del año 2001, con la agregación del punto 9 al artículo $38^{14}$, no se comprende la función pública que desempeñó el Ministerio de Administraciones Públicas en la adopción de las respuestas tecnológicas que requirió la asimilación del calificado como «Efecto 2000», con una representación pública condicionada por los conocimientos técnicos y las acreditadas aplicaciones del sector privado, cuyos representantes en la Comisión Nacional predeterminaron, de modo inevitable, las decisiones a adoptar, pues sobre el propio ámbito empresarial privado se proyectaba el grueso de los posibles efectos negativos ${ }^{15}$, en contraste con un sector público cuyas prácticas no superan los límites de los ordenadores personales con la excepciónes, singulares y asistemáticas, de la Agencia Estatal Tributaria y de la Tesorería de la Seguridad Social, sin poder obviar el Sistema de Interconexión

\footnotetext{
${ }^{13}$ El texto de la Ley 30/1992 dispuso: «Mediante convenios de colaboración suscritos entre las Administraciones Públicas, se establecerán sistemas de intercomunicación y coordinación de registros que garanticen su compatibilidad informática y la transmisión telemática de los asientos» y la Ley 4/1999 agrega a continuación «de los asientos»: «registrales y de las solicitudes, escritos, comunicaciones y documentos que se presenten en cualquiera de los registros».

${ }^{14}$ Ley 24/2001, de Medidas Fiscales, Administrativas y de Orden Social que, de modo complementario, incorpora la regulación de la práctica de la notificación telemática y de la presentación telemática de solicitudes y comunicaciones, por el nuevo punto 3 al artículo 59, y por la nueva Disposición adicional decimoctava a la Ley 30/1992-4/1999.

15 Creada por Acuerdo del Consejo de Ministro de 12 de junio de 1998, presidida por el Vicepresidente $2^{\circ}$ del Gobierno, e integrada por representantes de los Ministerios, del Consejo Superior de Informática, de las Cámaras Oficiales de Comercio, Industria y Navegación, de las Comunidades Autónomas y de la Administración Local. En comparecencia ante la Comisión de Redes Informáticas del Senado, don Jesús Colao Fernández, Adjunto a la Gerencia de Informática del Corte Inglés, informa de la metodología seguida y de las soluciones aportadas por los 105 profesionales que, de modo específico, asumieron la responsabilidad de resolver los problemas informáticos provocados por el cambio de siglo. Vid. Diario de Sesiones del Senado de 22 de marzo de 1999, p. 38.
} 
Bursátil, referente público inducido por la consolidada integración de la telemática en el sector financiero.

En el mismo contexto de inactividad administrativa para vertebrar el sistema telemático del conjunto de Administraciones del Estado descentralizado, no se comprende la posición del Ministerio de Industria y de la Fábrica Nacional de Moneda y Timbre, sin proyectar su dinámica sobre el Ministerio de Administraciones Públicas y la pendiente vertebración con Comunidades Autónomas y Ayuntamientos. También es incoherente en el conjunto del sistema institucional la posición de la Fabrica Nacional de Moneda y Timbre, en su condición de Autoridad Pública de Certificación Española, con su activa proyección sobre el sector privado de la seguridad en la red, y el Ministerio de Industria, Turismo y Comercio, con la Secretaría de Estado para la Sociedad de la Información la supervisión de la dinámica de un sector privado muy activo en el proceso de normalización de productos y, con una decisiva influencia en la homologación de criterios documentales telemáticos, de inevitable asimilación por las Administraciones públicas en sus demorados procesos de adaptación a los ya ineludibles tratamientos telemáticos de los procedimientos administrativos ${ }^{16}$.

El tenor literal del artículo 38.4, in fine, de la Ley 30/1992-4/1999 considera la figura de los convenios como instrumento que debe contribuir a materializar la interconexión. En consecuencia, la Disposición adicional 2a al precisar la informatización de los Registros y deferir su efectividad a la forma y a los plazos que determinen el Gobierno de las Comunidades Autónomas y de las Entidades Locales que integran la Administración Local, lo supedita sólo al grado de desarrollo de lo medios técnicos de que dispongan, cautela que se limita a lo establecido en su tenor literal y que no debiera haber contribuido a neutralizar el contenido básico de la inexcusable incorporación de la telemática, en coherente materialización del mandato imperativo del referido artículo 45 del mismo texto legal, criterio normativo básico muy distante de la Disposición final de la Ley 30/1992 que supeditaba a Acuerdo del Consejo de Ministros la efectividad material y temporal del derecho reconocido en el punto f) del artículo 35 (no presentar documentos no exigidos por las normas aplicables a los procedimientos, o que ya se encuentren en poder de la Administración).

Conforme al marco normativo, las Comunidades Autónomas y las Entidades Locales tienen que desarrollar las previsiones básicas para materializar la red administrativa telemática que permita, conforme al enunciado incorporado al precepto por la Ley 4/1999, que los ciudadanos puedan utilizar cualquier registro como referencia para la remisión al registro de cualquier

\footnotetext{
${ }^{16}$ Las Normas ISO (Internacional Organization for Standardization), con la trascendencia de la Norma ISO 7811, de grabación en tarjetas de identificación; ISO 8601, de representación de tiempo y fecha; ISO 8859, de codificaciones de caracteres; ISO 9960, de sistemas de archivos en CD-ROM, ISO 90009004, de sistemas de gestión de calidad, ISO 690-2, de documentación; ISO 10011, de auditoría.
} 
otra Administración a la que vayan destinados escritos, comunicaciones y documentos, objetivo que, si es bloqueado, como efectivamente lo es, por las Comunidades Autónomas y Entidades Locales que no han formalizado los convenios, generan agravios a sus ciudadanos y vecinos en relación con los ciudadanos de las Comunidades Autónomas y Entidades Locales convenidas y ya en red, en menoscabo de la garantía del tratamiento común ante ellas de los ciudadanos que garantiza el artículo 149.1.1 y 18 de la Constitución mediante la regulación de las condiciones básicas del régimen jurídico de las Administraciones públicas.

El resultado expresado contrasta con los objetivos expuestos con particular expresividad por la Exposición de Motivos de la Ley 30/1992, al precisar que «el régimen jurídico no es neutral en una dinámica de modernización del Estado» y proponerse establecer «una fluida relación entre las Administraciones y un marco jurídico de actuación común a todas ellas que permita a los particulares dirigirse a cualquiera de ellas con la certeza de que todas actúan con criterios homogéneos» y determinar que «la cooperación es un deber general, la esencial del modelo de organización del Estado autonómico que se configura como un deber recíproco de apoyo y mutua lealtad que no es preciso que se justifique en preceptos concretos», sin olvidar las precisiones relativas a la evaluación que la misma Exposición hace del «parque informático y telemático» de las Administraciones públicas, «limitado al funcionamiento interno, sin correspondencia relevante con la producción jurídica de su actividad relacionada con los ciudadanos», constatación que conduce a una contundente afirmación: «Las técnicas burocráticas formalistas, supuestamente garantistas, han caducado, por más que a algunos les parezcan inamovibles, y la Ley se abre a la tecnificación y modernización de la actuación administrativa en su vertiente de producción jurídica y a la adaptación permanente al ritmo de las innovaciones tecnológicas» ${ }^{17}$.

En contraste con los textos transcritos de la Exposición de Motivos de la Ley 30/1992, los casi tres quinquenios transcurridos, obligan a precisar que no han sido posible las innovaciones tecnológicas en la organización y gestión administrativa por no haber llegado el impulso político ni tan siquiera a articular la red telemática de las Administraciones públicas del Estado Español o Reino de España, donde la renuencia de Ayuntamientos y Comunidades Autónomas ha convergido con el bloqueo en la misma Administración General del Estado al Ministerio de Administraciones Públicas en los dos comprometidos envites legislativos de 1992 y 1999, también como forma implícita de perverso consenso político si se consideran los cambios en las mayorías políticas en ambos textos legales.

Notable es la brecha tecnológica entre los espectaculares desarrollos del sector privado asimilados por unos clientes que incorporan la tecnología con

${ }_{17}$ Puntos 3.5, 4.2 y 3, 5 in fine, de la Exposición de Motivos de la Ley 30/1992. 
independencia de su edad y estatus y un sector público incapaz de asumir los retos de la Ley de Régimen Jurídico de sus Administraciones y situarse al nivel de gestión del sector privado en sus relaciones con los ciudadanos.

La peligrosa pérdida de ejemplaridad que lo público ha tenido y debiera seguir teniendo para los ámbitos que tiene que conformar en función de los compromisos que le marcan los principios rectores de la política social y económica, concurre con la paradoja de que siga determinando conductas sociales en ámbitos donde no materializa su deber de actuar, como es el caso de las medidas de «Mejora en el funcionamiento de la Administración», objeto de la Ley 24/2005, de Reformas para el Impulso de la Productividad, con propuestas de «mejora en los trámites para los ciudadanos y las empresas», sintetizadas en el «impulso a la tramitación telemática» que imponen, a los Notarios y Registradores de la Propiedad la implantación obligatoria de sistemas telemáticos y la adecuación a los principios rectores de la firma electrónica, con la presentación de los documentos susceptibles de inscripción por los interesados por vía telemática, salvo indicación expresa en contrario, conjunto de medidas que establecen la metodología que tendrían que autoaplicar las Administraciones territoriales ${ }^{18}$.

En el fracaso de la tecnificación y modernización de la actuación administrativa y en el distanciamiento administrativo de las innovaciones tecnológicas confluye el bloqueo de la descentralización política y administrativa del Estado, obstaculizada y neutralizada por el neocentralismo de las capitales autonómicas en severo menoscabo de la autonomía local y en detrimento de la coherencia del conjunto institucional del Estado descentralizado y, como correlato de la coherencia del sistema administrativo, y como resultado último, en perjuicio de los ciudadanos retenidos en los neocentros autonómicos y minimizados en las potencialidades de la descentralización conclusa en las terminales de los municipios de la Europa de las ciudades de la que se desagrega España.

\section{LA INCORPORACION DEL PRINCIPIO DE BUENA} ADMINISTRACIÓN POR EL TRATADO POR EL QUE SE ESTABLECE UNA CONSTITUCIÓN PARA EUROPA COMO REQUERIMIENTOS PARA LA RECREACIÓN DEL SISTEMA ADMINISTRATIVO DEL ESTADO DESCENTRALIZADO ESPAÑOL, DESDE LA REFERENCIA BASILAR DE LA ADMINISTRACIÓN LOCAL

La polarización de la Ley de Modernización del Gobierno Local en el fortalecimiento del presidencialismo municipal y de los ejecutivos articulados

18 Artículos 27 y 28 de la Ley 24/2005. 
en su entorno sin la legitimidad de la elección directa del alcalde ${ }^{19}$, con el consecuente distanciamiento de la organización y de los métodos administrativos y, por indución, la relativización de la estructura organizativa profesionalizada de Secretaría-Registro-Archivo sin reparar en la incorporación a la Administración local de las nuevas tecnologías, se contrapone a los contenidos del Libro Blanco sobre la Gobernabilidad ${ }^{20}$ y su especial preocupación por respetar las estructuras de participación y de utilizar, conforme a las propuestas del Consejo Económico y Social y del Comité de las Regiones, las nuevas tecnologías como medio de racionalización administrativa ${ }^{21} \mathrm{y}$, en simultáneo, se contrapone a la síntesis de prácticas administrativas que incorpora el Derecho a una buena administración, y complementado por el Derecho de acceso a los documentos, artículos II-101 y II-102, del Tratado por el que se establece una Constitución para Europa.

\footnotetext{
${ }^{19}$ En los propios términos de la Exposición de Motivos de la Ley, punto I.6: «Atender a la necesidad de un liderazgo claro y diáfano ante la sociedad, lo que exige ejecutivos con gran capacidad de gestión para actuar rápida y eficazmente». En la misma línea, el punto III.5 de la Exposición de Motivos: «En materia de organización, debe destacarse que la Comisión de Gobierno pasa a denominarse «Junta de Gobierno Local», expresión que tiende a destacar la naturaleza ejecutiva de dicho órgano». El artículo 126. al regular la organización de la Junta de Gobierno Local dispone:
}

1. La Junta de Gobierno Local es el órgano que, bajo la Presidencia del Alcalde, colabora de forma colegiada en la función de dirección política que a éste corresponde, mediante el ejercicio de las funciones ejecutivas y administrativas que se señalan en el artículo 127 de esta Ley.

2. Corresponde al Alcalde nombrar y cesar libremente a los miembros de la Junta de Gobierno Local, cuyo número no podrá exceder de un tercio del número legal de miembros del Pleno, además del Alcalde.

El Alcalde podrá nombrar como miembros de la Junta de Gobierno Local a personas que no ostenten la condición de Concejales, siempre que su número no supere la mitad de sus miembros, excluido el Alcalde. Sus derechos económicos y prestaciones sociales serán de los miembros electivos.

20 El Libro Blanco sobre «La Gobernanza Europea» es muy preciso y rotundo en su punto de partida: «Los dirigentes políticos de toda Europa se enfrentan actualmente a una verdadera paradoja. Por una parte, los europeos esperan de ellos que encuentren soluciones a los grandes problemas que acucian a la sociedad. Pero, al mismo tiempo, esos mismos ciudadanos tienen cada vez menos confianza en las instituciones y en los políticos, o simplemente no están interesados en ellos». En función de esta dicotomía y para resolver sus disfunciones, el Libro Blanco propone: «Las instituciones democráticas y los representantes públicos tanto a nivel nacional como europeo pueden y deben tratar de conectar Europa a sus ciudadanos, como requisito previo a unas políticas pertinentes y efectivas». El Libro Blanco, en su propuesta de revisión institucional de los órganos y de las actuaciones de la Unión Europea, identifica, como factor determinante, marcado por la finalidad de materializar la acción comunitaria en resultados coherentes con los principios de la Unión Europea y por el determinismo de conseguir la efectiva materialización de los derechos de los ciudadanos europeos: «Llegar hasta el ciudadano por la vía de la democracia regional y local». Vid. La Gobernanza Europea. Libro Blanco COM (2001), C 287, DOCE 12.10.2001., punto III,1, p. 8.

${ }^{21}$ El Comité Económico y Social, conecta las nuevas tecnologías con la efectiva integración del parecer ciudadano, con su necesaria referencia de las estructuras administrativas y, en secuencia, conforme al criterio del Comité de las Regiones con los principios de proximidad, transparencia y acceso a la información, que integra en la organización telemática pública, la e-Administración o e-Governement, en las que la coherencia de los accesos informáticos tiene que incorporar precisión en los ámbitos organizativos y competenciales. Vid. Dictamen del Comité Económico y Social sobre «La Gobernanza Europea-Un Libro Blanco, cit., punto 3.2., y Dictamen del Comité de las Regiones de la Unión sobre el Libro Blanco de la Gobernanza Europea, cit., puntos 4.1-4.3, y 4.7. 
La Ley de Modernización del Gobierno Local incurre en la paradoja de fortalecer las competencias ejecutivas de los titulares de las alcaldías en el momento en que la acuñación del «Derecho a una buena administración», agrega, en sus contenidos, la suma integrada del Reglamento de Organización y Funcionamiento de las Corporaciones Locales y de la Ley 30/19924/1999, de Régimen Jurídico de las Administraciones Públicas, aportación española a la Constitución Europea desagregada de la más reciente reforma del régimen local.

El Libro Blanco sobre el Gobierno Local y el procedimiento de información pública de que ha sido objeto, decantado en el borrador del Anteproyecto de Ley Básica del Gobierno y la Administración Local ${ }^{22}$, incorpora esbozos que permiten apreciar signos de cambio en este significativo ámbito de la organización y de la gestión municipal.

El artículo 9.3 del borrador reconoce a los ciudadanos el derecho a obtener certificaciones acreditativas de los acuerdos de los órganos de las entidades locales, así como a consultar los archivos y registros en los términos que disponga la legislación de desarrollo del artículo 105, párrafo b) de la Constitución.

El artículo 27, bajo el epígrafe «Intercambio de información», dispone la regulación del deber de remisión por las entidades locales de los actos y acuerdos a la Administración General del Estado y especifica el deber de ésta y de las Comunidades Autónomas para facilitar el acceso de los representantes legales a los instrumentos de planificación, programación, proyección y gestión de obras y servicios que les afecten.

El artículo 72, bajo el epígrafe «Funciones públicas en las Entidades Locales», identifica la Secretaría, comprensiva de la fe pública y el asesoramiento.

Estas modestas aportaciones pueden y deben ser consideradas como el punto de partida que permita, en la decantación del borrador de anteproyecto a proyecto y Ley, reparar en que, cercano el treinta aniversario de la Constitución, es el momento de dejar de citar el artículo 105, b) y hacerlo objeto del oportuno y adecuado desarrollo y, al tiempo, ampliar a su ámbito natural el «intercambio de información» entre las Administraciones del Estado descentralizado, con integración del ciudadano, y en su directo beneficio, en el intercambio de datos entre las Administraciones, y precisar la consideración de la Administración local como receptáculo natural de las relaciones del ciudadano con cualquier otra Administración. Con ello se comenzaría a definir el estatuto del ciudadano de la sociedad de la información y del conocimiento ante el específico ámbito local, y como corolario contribuiría a que la Administración local pueda ser la coherente referencia interadministrativa del ciudadano mediante la recuperación de la función directiva de la

\footnotetext{
${ }^{22}$ Versión 22 noviembre 2005, www.fecam.es/docms/noticias/2005/borra_refor_ley\%207-1985.pdf y www.fac.info/ACTUALIDAD/BORRADOR\%20LBGAL-251105.doc
} 
interrelación Secretaría-Registro-Archivo en la gestión de la documentación municipal, en aras de la seguridad jurídica, de la racionalidad en la gestión y de la efectiva materialización de los derechos ciudadanos.

Significativas son actuaciones autonómicas que contribuyen a materializar la conexión telemática de la Comunidad Autónoma con sus Entidades Locales -mas allá de la atención a la propia estructura o de declaraciones retóricas que enfatizan sobre la sociedad de la información y del conocimientocon líneas de actuación como la desarrollada por la Comunidad Autónoma de Aragón, mediante la creación por la Ley 7/2001 de la Entidad Pública Aragonesa de Servicios Telemáticos, y regular el Portal de Servicios del Gobierno de Aragón por Decreto 325/2002, proyectado sobre las terminales municipales del coherente mapa comarcal de Aragón, mediante la creación de la Red Autonómica de Comunicaciones Institucionales ${ }^{23}$. En la Comunidad Autónoma de Extremadura el Plan de Modernización, Simplificación y Calidad 2004-2007 ha creado las infraestructuras informáticas necesarias para operar con un Sistema de Registro común para la Comunidad Autónoma y los Ayuntamientos y compartir las bases de datos de la Comunidad Autónoma, y se proyecta sobre los ciudadanos con la creación del Fichero Automatizado «Gestión del Correo Electrónico del Ciudadano» con las garantías requeridas por la Ley 15/1999, de Protección de Datos de Carácter Personal24. En línea coincidente, la Junta de Galicia ha creado, por Decreto 164/2005, el Registro Telemático que permite la presentación de solicitudes, escritos y comunicaciones, regula la atención al ciudadano y determina las oficinas de registro propias y concertadas con los ayuntamientos.

La presentación por el Ministro de Administraciones Públicas del proyecto de Sistema de Aplicaciones y Redes para las Administraciones (SARA) ${ }^{25}$ como sistema de comunicación entre las distintas Administraciones Públicas y la aprobación del nuevo Documento Nacional de Identidad con la incorporación de firma electrónica ${ }^{26}$, permiten recuperar, en terminología del propio Ministro, el concepto de «cerebro de la Administración», enriquecido, es posible añadir, por las dendritas de las Administraciones locales vertebradas sobre la estructura organizativa operativa de Secretaría-Registro-Archivo, como referencia para el rigor en la gestión municipal y como fehaciente materialización del efectivo servicio al ciudadano de la sociedad de la información y del conocimiento, mediante los instrumentos electrónicos, informáticos y telemáticos previstos por el artículo 45 de la Ley 30/1992-4/1999 de Régimen Jurídico de las Administraciones Públicas.

\footnotetext{
${ }^{23}$ Artículo 6.4 de la Ley 3/2202, de Creación de la Comarca del Cinca Medio, e incorporada a las sucesivas Leyes de creación de Comarcas de Aragón.

${ }^{24}$ Orden 22 de marzo de 2006, Diario Oficial de Extremadura 4 de abril.

25 Presentado en Gijón el 20 de diciembre de 2005

${ }^{26}$ Real Decreto 1553/2005, de 23 de diciembre, por el que se regula la expedición del documento nacional de identidad y sus certificados de firma electrónica.
} 
La acuñación del concepto de «buena administración» por el artículo II. 101 del Tratado por el que se establece una Constitución para Europa, debe incentivar a cerebrar a las Administraciones del Estado descentralizado español, desde la base de cada unidad de la Administración Local a la cúspide de la Administración General del Estado, por la poderosa razón de que el precepto en el que la Unión Europea sintetiza los contenidos de la «buena administración», no es más que la síntesis de los derechos de los ciudadanos ante las Administraciones públicas del innovador artículo 35 de la Ley $30 / 1992$ española, de tal modo que el contenido de su punto $b)^{27}$ ha sido transferido al punto b) del artículo II-101 del Tratado, con la pequeña pero significativa variante de sustituir el concepto de procedimiento por el de «expediente ${ }^{28}$, con integración, según hemos podido apreciar, de un concepto tan preciso y tan peculiar en los reglamentos locales y, en particular, del Reglamento de Organización y Funcionamiento.

El derecho a una buena administración requiere recuperar, en el ámbito local y en el conjunto de las Administraciones, la interrelación SecretaríaRegistro-Archivo, desvirtuada en el ámbito de las Administraciones que, como referencia organizativa y operativa profesionalizada, muestra su potente funcionalidad en el ámbito de las organizaciones empresariales privadas, por razones de ineludible coherencia organizativa y operativa en la rentabilidad de los capitales privados.

En correspondencia, la racionalidad en la aplicación de los fondos presupuestarios públicos para satisfacer los objetivos comunitarios a los que tienen que adecuarse sus gastos consuntivos y sus partidas de inversión, requieren integrar en la organización y en los procedimientos administrativos la correlación Secretaría-Registro-Archivo, históricamente prevista para el ámbito público, como instrumento garante del vínculo de la actividad administrativa al cumplimiento de la legalidad y de racionalidad institucional. Premisa estructural que, en el Estado descentralizado, demanda vertebrar el sistema administrativo con base en las Entidades Locales como referencia institucional mas próxima al ciudadano, para proyectarse en las estructuras regionales de las Comunidades Autónomas y con la referencia última de la Administración General del Estado, en coherente aplicación de la metodología establecida por el Libro Blanco de la Gobernabilidad que sintetiza el artículo 137 de la Constitución Española.

En las terminales telemáticas de la e-Administración española en los Entes Locales, el ciudadano - español o comunitario y con independencia de su vecindad administrativa y de su residencia ocasional- debiera sentir el carácter unitivo del Estado Español mediante la aplicación de un soporte téc-

\footnotetext{
${ }^{27}$ «A conocer, en cualquier momento, el estado de la tramitación de los procedimientos en los que tenga la condición de interesados».

28 «a acceder al expediente que le concierna, dentro de los intereses legítimos de la confidencialidad y del secreto profesional».
} 
nico muy definido y bien practicado por el sector privado ${ }^{29}$, en sustitución de la anarquía institucional que, como resultado de la libre ocurrencia de cada Comunidad Autónoma, o de cada Ayuntamiento o Diputación Provincial, ha conducido, hasta el momento, a que se concierte, o no, con el Ministerio de Administraciones Públicas, y permita, o no, la recepción de documentación dirigida a otras instancias administrativas. Estos resultados parangonables con el disparate institucional, han estado y están en manifiesta contradicción con las Cumbres Europeas de Lisboa y Sevilla, incoherencia que tiene que contribuir a la efectiva formalización del anunciado Sistema de Aplicaciones y Redes para las Administraciones, embrión del sistema telemático de las Administraciones del Estado descentralizado, llamado a desarrollarse y consolidarse con la activa contribución del nuevo Documento Nacional de Identidad que, por agregar la firma electrónica, incorpora, al ciudadano y a las terminales de Registro, Archivo y Secretaría de las Entidades Locales, a la dinámica integrada del conjunto institucional del sistema administrativo.

\footnotetext{
${ }_{29}$ Al respecto, la publicación de Telefónica: La sociedad de la información en España, Madrid 2005, con la previsión de las conexiones telemáticas para los Ayuntamientos, en nueve áreas que sintetizan la estructura organizativa y operativa de las Entidades Locales.
} 